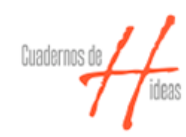

Cuadernos de $\mathrm{H}$ ideas

ISSN: 2313-9048

cuadernosdehideas@perio.unlp.edu.ar

Universidad Nacional de La Plata

Argentina

\title{
De lo local a lo global en el espacio de las historias conectadas
}

Carzolio, María Inés

De lo local a lo global en el espacio de las historias conectadas

Cuadernos de $\mathrm{H}$ ideas, vol. 14, núm. 14, 2020

Universidad Nacional de La Plata, Argentina

DOI: https://doi.org/10.24215/23139048e036 


\section{De lo local a lo global en el espacio de las historias conectadas}

From local to global in connected histories' space

Maria Inés Carzolio

DOI: https://doi.org/10.24215/23139048e036

Universidad Nacional de Rosario / Universidad Nacional

de La Plata, Argentina

micarzolio@gmail.com

(D) http://orcid.org/0000-0001-9594-9099

\section{Resumen:}

El presente artículo tiene por finalidad exponer de manera sucinta desde una perspectiva crítico analítica, las principales líneas que abonan lo que una historiadora ha llamado recientemente "giro global" en el estudio de la historia atlántica, estableciendo en términos generales del problema, las fuentes historiográficas en que se abrevan.

Palabras Clave: Historia Atlántica, Historia Global, Historia Local, Conexiones, Circulación.

\section{Resumo:}

O objetivo deste artigo é apresentar sucintamente, de uma perspectiva crítico-analítica, as principais linhas que apoiam o que um historiador chamou recentemente de "virada global" no estudo da história do Atlântico, estabelecendo em termos gerais o problema, as fontes historiográfico em que se baseiam.

PalaVras-chave: Historia Atlântica, historia global, historia local, conexoes, circulaçao.

\section{Abstract:}

The purpose of this article is to expose in raised way, from a critical and analytical perspective, the main lines that contribute to what a historian has called "global turn" in the study of Atlantic history, establishing in general terms, the historiographical sources in which they built on.

KEYWORDS: Atlantic History, Global history, Local history, connections, circulation.

En el comienzo fue la historia atlántica. En el año 2000, Elliott dio la bienvenida a su aparición. La unificación del Atlántico como vínculo entre Europa, África y América, venía a saldar la construcción de los tres Atlánticos surgidos en el siglo XVI, definidos por condiciones climáticas y medioambientales. En el Norte, el inhóspito mar de pesca de Terranova, atravesado por una ruta que se ramificaría hacia el Sur y que acabaría por convertirse en el Atlántico de los británicos, franceses y holandeses, desde la Bahía de Hudson hasta la desembocadura del Delaware. El segundo Atlántico fue el español de la carrera de Indias, que unía a Sevilla con el Caribe y la América continental. El tercero era el luso, originado por el desembarco de Cabral en el Brasil. Seguía la tendencia iniciada por Verlinden en 1953, que procuró mostrar cómo desde los comienzos de la colonización americana "la unidad histórica de Europa fue de forma creciente el principal componente de la unidad histórica más amplia nacida de la expansión europea en la zona de civilización atlántica” (Verlinden en Elliott, 2000, p. 22). ${ }^{1}$ Pero más tarde, Elliott registró el impacto de la globalización en la generación actual de historiadores haciéndolos a su parecer "poco pacientes ante narrativas históricas confinadas a unidades nacionales individuales y a entidades territoriales" y que por consiguiente tratan "de situar sus historias en contextos más amplios tanto a nivel transnacional como a nivel global". Puesto que siendo "el movimiento y la conexión" características fundamentales de nuestro tiempo, es natural que traten de adaptar a ese marco la escritura de la historia contemporánea (Elliott, 2012, p. 22). Es expresión del esfuerzo de una perspectiva renovada sobre la historia para enfrentar los desafíos que imponen, a las ciencias históricas, los 
fenómenos actuales de globalización (Conrad, 2017). ${ }^{2}$ Pero no se trata solo de la ampliación del ámbito de la reflexión. Otro importante investigador, Kamen (2003), presenta una construcción historiográfica en la que el Imperio español de la primera modernidad como una obra colectiva, que se erige al margen de las diferenciaciones de origen (españoles, pero asimismo italianos, belgas, alemanes y chinos) o de clase entre los grupos (colonizadores, indios reducidos a servidumbre, esclavos negros, marginados, inmigrantes), o aun de sexos. No solo rechaza el eurocentrismo sino también la situación objetiva de cada cual en el organigrama del dominio imperial (Kamen, 2003). Contribuyeron a la formación del Imperio los Tlaxcaltecas que combatieron en Tenochtitlán, los africanos que atravesaban el Atlántico en los barcos negreros portugueses, ingleses y holandeses. Pero lo que para muchos fue epopeya, para otros fue irreparable desolación y eso también forma parte de la historia global.

Hace unos años, Bertrand (2013) publicó un artículo titulado "Historia global, historias conectadas: ¿un giro historiográfico?”, en el cual se preguntaba por la naturaleza de aquéllas, si se trataba de una expansión del estudio de las «áreas culturales» o una revolución metodológica. En el último caso cabía interrogarse acerca de si se trataba de un "juego de escalas" (Bertrand, 2015, 7) o de focos, indagables a partir solamente de archivos europeos, o si cabía dedicar mayor atención a las fuentes extraeuropeas. Pero no eran las únicas preocupaciones de Bertrand. Para él se trata de una historia conectada social o cultural de las zonas de contacto de mundos distantes, que se aparta del europeocentrismo para tratar de elaborar una "historia simétrica" (Bertrand, 2015, nota 17) en el sentido de otorgar voz al conjunto de actores en presencia, vale decir, si se empleaba para ello también documentación y archivos de los mundos en cuestión. Esto significa que las historias africanas, americanas, asiáticas, no se sitúan ya en los márgenes de la investigación y de la enseñanza universitaria, sino en espacios centrales. ${ }^{3} \mathrm{Su}$ revisión de las corrientes que nutrieron el «giro global» (Aram, 2019) rememora y reseña en primer lugar los estudios acerca de los contactos de las «áreas culturales» desde los años 60 del Índico hasta el Imperio otomano o de los pueblos africanos hasta la primera década del siglo XXI, y las críticas que suscitó su posición francocentrada. En segundo lugar, se ocupa de la cuestión de la escala de análisis de lo global, que durante la Edad Moderna implica la cuestión del análisis de la "la conciencia de la globalidad" posible en los actores, conduciendo a probables anacronismos o bien una historia de las elites, ya que supone un horizonte del imaginario historiográfico que variaría según el grado de inclusión en las culturas eruditas de su tiempo. ${ }^{4}$ Por su parte, Conrad (2017) pone en guardia en cuanto a su empleo:

Cuando se dejan de lado las cuestiones de la jerarquía y la explotación, el interés por las conexiones puede desdibujar -
obstaculizar, incluso - la adecuada comprensión de los perfiles del pasado global. Cuando no tenemos en cuenta la estructura
del poder, damos carácter de agente a todo el que interviene en las interacciones e intercambios; y al celebrar la movilidad,
se corre el peligro de hacer caso omiso de las estructuras que la controlan. Los movimientos transfronterizos pueden salvar
las diferencias entre sociedades, pero también exacerbar los conflictos. Tanto los aristócratas europeos que se embarcaban
en el Grand Tour como los esclavos europeos enviados a América cruzaban fronteras 'políticas y culturales, pero no hace
falta ahondar mucho para ver que tratar ambos casos como meros ejemplos de "conexiones" comportaba una intensa carga
ideológica (p. 68).

Más problemática aun sería la cuestión de la oposición entre lo "micro" y lo "macro", pues la variación del "foco del objetivo" modifica "la forma y la trama" (Revel, 1996, p. 19). Sin embargo, utilizando lo "global" (Bertrand, 2015, p. 12) con precauciones, permitiría darse cuenta de la diversidad de las "formas de vida" (Bertrand, 2015, nota 37) que hicieron posibles los contactos entre sociedades distantes. Pero Bertrand aboga por una tercera vía, que es la de la "historia conectada" (Bertrand, 2015, p. 13), donde no existe lo "global" como nivel autónomo sino las conexiones establecidas por los actores mismos (no "la escala" sino "el foco"), que exigen una simetría documental -es decir, contacto con pueblos que poseen crónicas, anales o relatos escritos-que "obliga a solicitar tanto y del mismo modo,...las fuentes extraeuropeas comolas fuentes europeas" (Bertrand, 2015, nota 40). Sin embargo, el encuentro entre europeos, malayos, mongoles o javaneses no revistió para todos ellos la misma importancia y eso se reflejó en su historiografía, lo cual desautorizó la 
temática de las "miradas cruzadas" (Bertrand, 2015, pp. 14-15). ${ }^{5}$ Mientras los europeos escribieron relatos significativos de estos encuentros, los cronistas locales omitieron a menudo la llegada de aquéllos. Si la primera expedición holandesa que recaló en la provincia indonesia de Banten, al norte de Java, en junio de 1596 recibió un minucioso tratamiento en las crónicas elaboradas en las Provincias Unidas, no es siquiera mencionada en los anales reales del sultanado (SajarahBanten, c. 1626), observa Bertrand, así como tampoco la llegada de un emisario británico en Agra entre 1615 y 1618, mereció para los escribas mongoles la misma atención que las embajadas persas u otomanas, que relataron detalladamente en el Tubuki-Jahagiri o crónica del reino de Jahangir (1605-1627). La razón del desinterés se debía a que los estados asiáticos mantenían relaciones fluidas con el imperio otomano y con la India mogola, así como con la China imperial, "vectores de la circulación de los saberes literarios, políticos y religiosos" (Bertrand, 2015, p. 15) y también de oportunidades comerciales o de peligros militares, en tanto que la relación con Europa no ofrecía ese interés. Un americanista pondría en duda además su posibilidad en el Nuevo Mundo cuando algunos de los estados en cuestión no conservaron una cultura escrita. Para Bertrand esta historia conectada no es una simple corriente de la historia global, puesto que una parte importante de la producción anglófona en «historia global» se construye sobre fuentes exclusivamente europeas, esa global history pertenece a la historia europea (Bertrand, 2015, p. 17). Ambas formas comparten una crítica del Eurocentrismo como versión mitificada del "milagro europeo" (Jones, 1981, en castellano, 1990), ${ }^{6}$ pero mientras la historia global lo hace bajo el modo de la historia comparada, la conectada desalienta las comparaciones estructurales y explora los registros de entendimiento práctico entre los actores, vale decir, se basa en el concepto de integración (Conrad, 2017). De allí su predilección por las biografías de los «mediadores» y de los autores mestizos, razón por la cual alerta sobre la diferencia entre las concepciones del individuo histórico como agente o como actor.

En cuanto al debate entre historia local e historia global, los opositores a esta última han puesto de manifiesto que el historiador suele trabajar con documentos que son siempre «locales» y que nutrieron los relatos de las ciudades, a partir del Renacimiento. Sin ir tan atrás, en la década de los 60 del siglo XX, la historia urbana convivió con la historia regional, fruto del interés por la historia comparativa que cotejaba y confrontaba los datos obtenidos de escenarios más extensos que el local. ${ }^{7}$ Pero la historia cultural, cuyo interés se centró a menudo tanto en la historia de los intermediarios culturales como en la de lugares diminutos, halló que el comportamiento particular de éstos puede revelar una realidad de carácter general. ${ }^{8}$

Dicho esto, debemos recordar que "la historia global se define -según comenta Martínez Shaw (2015b)por un cúmulo de microorganismos que garantizan su supervivencia" aludiendo a la miríada de centros de producción, de puertos de importación y exportación y de consumo, de agentes diseminados por todas las geografías (cultivadores, artesanos, comerciantes por mayor y menor, mercaderes, armadores, marinos, consignatarios... y finalmente, consumidores). La historia local, la historia regional, la historia global serían etapas de una misma realidad. La ciudad de México, situada en el Imperio Hispánico a medio camino de las rutas hacia el continente asiático se convierte en el siglo XVII en un centro del comercio intercontinental entre Europa, América y Asia. Centro de unas comunicaciones y de un comercio local, pero también intercontinental y naturalmente, internacional (Gruzinski, 2004). ${ }^{10} \mathrm{Tal}$ historia se puede aplicar a la comunicación entre mundos muy distantes entre sí, o identificar las situaciones más locales, las interdependencias que los vinculan a regiones lejanas sin que los actores tengan siempre una percepción clara de ello. La unión inseparable de lo global y lo local, el mundo y la patria en los países de habla hispana, pueden haber llevado a algunos a proponer el concepto de «glocal», que según Chartier (2001), acertadamente, aunque no con elegancia, para designar los procesos por los cuales referencias compartidas, modelos impuestos, textos y bienes circulantes a escala planetaria son apropiados para tener sentido en un tiempo y unos lugares particulares.

Otros autores están atentos a los contenidos ideológicos: el surgimiento de la historia global está motivado \#según Martínez Shaw (2015b)\# por el reconocimiento del impacto presente del proceso de globalización 
sobre la economía, la sociedad y la cultura, al cual, desde un punto de vista europeocéntrico, se lo ve como una nueva etapa de la expansión europea sobre otros continentes, que se inicia en el siglo XVI. Esto ha tenido, para él, el efecto pernicioso de marginar las historias de los mundos extraeuropeos y de bastardear la comprensión profunda de la intercomunicación entre todos los continentes potenciando un discurso unidireccional, lo que reafirmaría la conceptuación de Bertrand acerca de que se trataría de historia europea.

En cuanto a la cronología, Martínez Shaw (2015a) propone una fecha concreta para su origen: el lapso que transcurre entre 1492 y 1522, que abarca la llegada de Colón a América (1492), la llegada a la India de Vasco de Gama (1498), el acceso al Mar del Sur (océano Pacífico) por Vasco Núñez de Balboa (1513) y la primera circunnavegación del globo terráqueo por la expedición Magallanes-Elcano (1522). Se inició así una red de intercambios (humanos, biológicos, agropecuarios, culturales y económicos) a partir de redes planetarias. Martínez Shaw (2015a) considera los llamados sistemas atlánticos como subsistemas dentro de la economía mundial que abarca también el Índico y el Pacífico. Ch. Bayly ha propuesto arbitrariamente otra cronología en tres fases: la globalización arcaica, desde la antigüedad hasta 1750, la protoglobalización que alcanzaría a 1850 y la actual o poscolonial, hasta la actualidad (Bayly, 2010).

Hausberger (2018) propone otra más razonable como comienzo de la globalización:

Alrededor de 1500, las macrorregiones de Eurasia (Europa, el mundo islámico, la India, China) y de América (Mesoamérica, el espacio andino), que habían desarrollado características distintivas con anterioridad, fueron conectadas de forma definitiva por la expansión ibérica (p. 235).

La primera globalización o primera mundialización -globalización temprana para Hausberger- fue una realidad multifocal, y el comienzo de una verdadera historia universal (Martínez Shaw, 2018). ${ }^{11}$ La plata americana fue el principal agente de esa primera globalización (Martínez Shaw, 2015). ${ }^{12}$ A partir de ese momento todas las partes del mundo que hasta entonces habían mantenido escasas o inexistentes relaciones entre sí, comenzaron a componer un solo mundo: el mundo interconectado de la historia global (Hausberger, 2018; Hausberger \& Pani, 2018; Conrad, 2017).

Una de las consecuencias insospechadas de la globalización ha sido la recuperación historiográfica de la posibilidad de grandes narrativas, capaces de ofrecer alternativas a la irrupción de un presente interconectado a escala mundial. Otras han sido tanto el renacimiento de la historia comparada (Conrad, 2017) ${ }^{13}$ como la aparición de la misma historia global -sobre todo la angloamericana- y como contraste, la resurrección de los nacionalismos políticos e historiográficos, así como la recuperación del relato, que tienen que ver con la necesidad de explicar lo que la contemporaneidad percibe como una creciente globalización del orbe. La importancia de la historia global es tal en la actualidad que D. Armitage, advirtió en un reportaje que, en el presente, si no se está cumpliendo un proyecto explícitamente "trasnacional, internacional o global", hay que explicar por qué (Etchechuri Barrera \& Rodríguez Aycaguer, 2018, nota 1). Ello es notorio en los países de lengua inglesa, donde continuamente aparecen nuevos manuales de Global History, World History, Connected History o Transnacional History -títulos que se emplean casi como sinónimos-, cuyo objetivo común suele ser la superación del europeocentrismo, de las escalas y categorías del Estado-nación, de la territorialización de los hechos o fenómenos estudiados y que comparten un grupo de conceptos comunes al campo de los estudios globales. ${ }^{14}$ Si las raíces de la historia global se hallan en la historiografía francesa de la Escuela de los Annales, su escenario principal es sobre todo Estados Unidos (Hausberger \& Pani, 2018).

Conrad (2017), que ha elaborado una notable síntesis ya citada para proporcionar una comprensión mayor del complejo panorama actual de la historia global, enumera las tres posibilidades de su probable desarrollo: 1) como la historia del todo, 2) como la historia de las conexiones y 3) como una historia basada en el concepto de integración o de las conexiones. La primera es la historia de cuanto ha sucedido en la Tierra. ${ }^{15}$ Para ello, algunos intentan capturar la realidad global durante un período determinado, otros abarcan milenios y por fin, ciertos historiadores parten del Big Bang, pero todos ellos -en su mayoría pertenecientes al ámbito anglosajón- pretenden cubrir la totalidad planetaria. Pero también pueden ocuparse de la historia de un 
imperio, del azúcar, del té, del chocolate, de la religión, de la guerra, es decir tanto de las formas de la política, la religión o las pautas de consumo. ${ }^{16}$ La segunda se basa en la idea de que ninguna sociedad, nación o civilización existe en forma aislada y abarca gran variedad de temas: circulación de personas, de ideas, o del comercio de larga distancia, aunque el alcance de las redes que implica es heterogéneo. En todos los casos se ocupa del carácter interconectado del mundo, pero de modelos de intercambio regular y sostenido que hayan tenido trascendencia para el desarrollo ulterior de las sociedades conectadas. ${ }^{17}$ Pero Conrad se interesa fundamentalmente por el tercer modelo, el de la historia basada en las conexiones, tomando como ejemplo la obra de Hill (2008) sobre el surgimiento de la historiografía moderna en Francia, Estados Unidos y Japón a finales del siglo XIX. Todas estas naciones tuvieron que hacer frente a problemas internos y participaban de la reestructuración del orden del mundo, derivado del capitalismo y del imperialismo. En cada caso, la historiografía sirvió para fundamentar el nacimiento del estado-nación y su jerarquía en el nuevo orden. La obra de Hill (2008) se refiere a las condiciones globales que dieron forma a los relatos históricos emergentes en cada caso.

Conrad (2017) sostiene que la historia global es a la vez un objeto de estudio y una forma particular de entender la historia, vale decir, un proceso, un tema, y una perspectiva, una metodología. Se puede enfocar el problema de la esclavitud desde diferentes vertientes de la historia social (económica, de género, demográficas, etc.) pero también se la puede situar en un contexto global, centrándose en otras cuestiones como la creación de un espacio trasatlántico, la vinculación de los problemas de la esclavitud con el estudio de las rutas esclavistas del Sahara y del Índico o comparándolas con otras formas de cautiverio. Como perspectiva, la historia global puede no ocuparse del mundo entero sino de ciertos espacios, pero teniendo en cuenta las condiciones globales y estructurales. No es historia universal ni macrohistoria. En realidad, la investigación sobre el Atlántico es un campo especialmente fértil para la historia global y la investigación transnacional, muchas veces relacionada con el desarrollo de la propia Europa (ruta de la seda, redes asiáticas), los procesos de territorialización y desterritorialización, el problema de las unidades de estudio, el de las escalas (Conrad, 2017).

Desde el punto de vista de la realidad de las condiciones universitarias del mundo angloamericano tiene un costo: abre el ángulo de visión, pero deberá disputar el espacio a la historia nacional y su victoria conduciría a veces al sacrificio de algunos campos relacionados, como la historia medieval.

Más allá de mostrar la heterogeneidad y complejidad de la perspectiva global, Conrad (2017) se preocupa por la política del enfoque global: en nuestro presente globalizado, la historia global contribuiría a dar significado al mundo en el que vivimos. En otras palabras, su promesa utópica es la de convertirnos en ciudadanos del mundo. Muchos grandes procesos (movimientos políticos, ideologías globales, crisis económicas y financieras, la expansión de las comunicaciones basada en Internet) ya no se pueden estudiar ni comprender en forma aislada. Agrego otro ejemplo: los desastres provocados por el cambio climático -y ahora mismo, una pandemia- nos hace conscientes de que todos habitamos el mismo planeta y compartimos -o pretendemos hacerlo- sus recursos. La mirada cosmopolita no es una visión defendida por todos. Quienes la defienden, a veces lo hacen para exaltar su propia nación. La historia mundial, popular en China, se asocia a la condición del país como potencia política y económica y a veces sirve de contexto en el que cabe explicar y promover el crecimiento de la nación. Las perspectivas globales sirven a las clases medias internacionales, para justificación de los mercados. Pero la historia global se puede usar también como metodología «que ponga en cuestión la teleología de la globalización» mediante la situación de los procesos y acontecimientos en contextos globales concretos. Por otra parte, los historiadores pueden recordarnos que las estructuras globales son siempre resultado de proyectos de globalización y por lo tanto, persiguen realizar sus propios intereses y programas. Las explicaciones globales nos hacen ir más allá de las explicaciones endógenas y genealógicas que atribuyen la prosperidad o las privaciones a sociedades, culturas o personas concretas. Pero como se tiende a describir grandes procesos «anónimos», sin sujetos nítidos, o sin responsables. 
Por otro lado, a pesar de la retórica antieurocéntrica, puesto que la historia global tiene un costo, solo puede prosperar donde hay gobiernos o fundaciones que financian los estudios. Hasta ahora se dedican al estudio de las relaciones establecidas por lo que llamamos Occidente, con el resto del mundo.

\section{REFERENCIAS}

Adelman, J. (2017). “¿What is Global History Now?”, AEOIN. Recuperado de: https://aeon.co/essays/is-global-hist ory-still-possible-or-has-it-had-its-moment

Aram, B. (2019). “¿Entre dos mares? Reflexiones a partir de la Historia Atlántica y hacía tres conceptos de la Historia Global”, Nuevo Mundo Mundos Nuevos. Recuperado de: http://journals.openedition.org/nuevomundo/76702

Bayly, Ch. (2010). El nacimiento del mundo moderno. 1790-1914. Madrid: Siglo XXI

Bertrand, R. (2007). "Rencontres impériales. L'histoire connectée et les relations euro-asiatiques, Revue d'histoire moderne et contemporaine, 54(4 bis),69-89. Recuperado de: https://www.cairn.info/revue-d-histoire-moderneet-contemporaine-2007-5-page-69.htm

Bertrand, R. (2013). “Histoire globale, histories conectées: ¿̨un tournant historiographique?”. En Caillé, A. et Dufoix, S. (dir.) Le "tournant globale” des sciences sociales, pp. 44-66. París: La Découverte.

Bertrand, R. (2015). "Historia global, historias conectadas: ¿un giro historiográfico?" [Trad. D. Barriera], Prohistoria, $X V I I I(24), 3-20$. Recuperado de: https://dialnet.unirioja.es/servlet/articulo?codigo $=5460312$

Bonalian, M. y Hausberger, B., (2018). "Consideraciones sobre el comercio y el papel de la plata hispanoamericana en la temprana globalización, siglos XVI-XIX”, Historia Mexicana, LXVIII(1),197-236. Recuperado de: https://h istoriamexicana.colmex.mx/index.php/RHM/article/view/3641/3550

Braudel, F. (1979). Civilisation matérielle, économie et capitalisme, XVe-XVIIIe siècle, 3 vols. Paris: Armand Colin

Burbank, J. y Cooper, F. (2010). Empires in World History: Power and the Politics of Difference. Princeton: Princeton University Press

Burbank, J. y Cooper, F (2011). Imperios: una nueva visión de la historia universal. Barcelona: Crítica.

Chacón, F. (1979). Murcia en la Centuria del Quinientos. Murcia: Universidad de Murcia

Chartier, R. (2001). “La conscience de la globalité (commentaire)", Annales HSS, janvier-fevrier, 1, 119-124

Chaunu, P. y H. (1955-1959). Seville et l'Atlantique. 1504-1650, 8 tomos. París: SEVPEN

Cipolla, C. (1980). Faith, Reason and the Plague in Seventeenth-Century Tuscany.Ithaca: Cornell University Press

Conrad, S. (2017). Historia global. Una nueva visión para el mundo actual. Barcelona: Crítica

Contreras, J. (1992). Sotos contra Riquelmes. Madrid: Anaya \&Mario Muchnik.

Darwin, J. (2007). After Tamerlane: The Global History of Empire. London: Allen Lane

Darwin, J. (2012). El sueño del imperio: auge y caída de los imperios globales 1400-2000. Madrid: Taurus

Elliott, J. H (2000). "En búsqueda de la Historia Atlántica”. En XIV Coloquio de Historia Canario-Americana, pp. 20-36. Las Palmas de Gran Canaria: Cabildo de Gran Canaria

Elliott, J. H (2012). "Reflexiones sobre una unión fracasada”, Espacio, Tiempo y Forma, Serie IV, Historia Moderna, t. 25, 21-36. Recuperado de: http://revistas.uned.es/index.php/ETFIV/article/view/11946/11349

Etchechuri Barrera, M. Y Rodríguez Aycaguer, A. M. (2018). "De las historias nacionales a las circulaciones globales: redes, prácticas y saberes entre América y Europa (siglos XIX y XX)”. Claves. Revista de Historia, 4(7), 1-8. Recuperado de: https://ojs.fhce.edu.uy/index.php/claves/article/view/285/228

Faroqhi, S. (1999). Approaching Ottoman J-listory: An Introduction to the Sources.Cambridge: Cambridge University Press

Fernández-Armesto, F. y Sacks, B. (2012). “Networks, Interactions, and Connective History”. En D. Northrop (ed.) A Companion to World History, pp. 303-321. Oxford: Willey-Blackwell

Fernández-Armesto, F. (2005). Breve historia de la humanidad. Barcelona: Edic. B

Games, A. (1999). "Teaching Atlantic History”, Itinerario, 23(2),162-174 
Ginzburg, C. (1976). Il formaggio e i vermi. Ilcosmodi un mugnaio del '500. Torino: Einaudi

Ginzburg, C. (2009). El queso y los gusanos. El cosmos de un molinero del siglo XVI. Barcelona: Península.

Godechot, J.. y Palmer, R. (1955). "Le problème de l'Atlantique”. En Comitatointernationale di scienzestoriche, Xe Congressointernazionale, vol. 5, pp.175-239. Florencia: Sansoni

Godechot, J. (1956). La Grande Nation: L'expansion révolutionnaire de la France dans le monde de 1789-1799, 2 vols. París: Aubier

Godechot, J. (1969). Las revoluciones (1770-1779). Barcelona: Labor

Goubert, P. (1960). Beauvais et la Beauvaisis de 1600 a 1730. París: SEVPEN

Gruzinski S. y Subrahmanyan, S. (2000). «Perspectives on Global History: Concepts and methodology/ Mondialisation de l'histoire: concepts et méthodologie». En Proceedings/Actes, 19th International Congress of Historical Sciences/XIXe Congrès International des Sciences Historiques, pp. 3-52. Oslo

Gruzinski, S. (2001). "Les mondes mêles de la Monarchie catholique et autres "connected" histories", Annales H.S.S, 56(1),85-117. Recuperado de: https://www.persee.fr/doc/ahess_0395-2649_2001_num_56_1_279935

Gruzinski, S. (2004). Les quatre parties du monde. Histoire d'une mondialisation. París: La Martinière

Guidi, J. Y Armitage, D. (2014). The History Manifesto. Cambridge: Cambridge University Press

Hausberger, B. y Pani, E. (2018). “Historia Global. Presentación”, Historia Mexicana, 68(1), 177-193. Recuperado de: https://historiamexicana.colmex.mx/index.php/RHM/article/view/3640

Hausberger, B.. (2018). Historia minima de la globalización temprana. México: El Colegio de México

Hausberger, B. (2019). "La globalización temprana. Réplica a Mariano Bonalian”, en Historia Mexicana, 68(4), 1831-1838. Recuperado de: https://historiamexicana.colmex.mx/index.php/RHM/article/view/3861/3820

Hill, CH. L. (2008). National History and the World of Nations: Capital, State, and the Rhetoric of History in Japan, France, and United States. Durham: Duke University Press

Hyden-Hanscho, V., Pieper, R. y Stangl, W. (eds.) (2013). Cultural Exchange and Consumption Patterns in the Age of Enlightenment. Europe and the Atlantic World. Recuperado de: https://winklerverlag.com/v1958x/v1958 -00.pdf

Jones, E. (1981). The European Miracle. Environments, Economies and Geopolitics in the History of Europe and Asia. Australia: Cambridge University Press

Jones, E. (1990). El milagro europeo. Madrid: Alianza.

Kamen, H. (2003). Imperio. La forja de España como potencia mundial. Madrid: Aguilar

Le Roy Ladurie, E. (1966). Les Paysans de Languedoc, 2vols. Paris, S.E.V.P.E.N.

Le Roy Ladurie, E. (1975). Montaillou, villageoccitan, de 1294 a 1324 [Montaillou, una aldea occitana de 1294 a 1324]. Paris: Gallimard

Levi, G. (1985). L'eredità immateriale: carriera di un esorcista nel Piemonte del Seicento [La herencia inmaterial. La historia de un exorcista piamontés del siglo XVII]. Torino: Einaudi

Levi, G. (2018). "Microhistoria e Historia Global”, Historia Critica, 69, julio-septiembre, 21-35.Recuperado de: http s://revistas.uniandes.edu.co/doi/pdf/10.7440/histcrit69.2018.02

Macfarlane, A. y Martin, G. (2002). Glass: a World History [La historia invisible: el vidrio: el material que cambió el mundo]. Chicago: Chicago University Press

Martínez Shaw, C. (2015a). “La plata española, catalizador de la primera globalización”. En J. J., Iglesias Rodríguez, R. M., Pérez García y M. F. Fernández Chaves (coords.) Comercio y cultura en la Edad Moderna. Actas de la XIII Reunión Cientifica de la Fundación Española de Historia Moderna, 2. Vols., Vol. 1, pp. 21-46. Sevilla: U. de Sevilla

Martínez Shaw, C. (2015b), "De la historia local a la historia global". Discurso de Ingreso. Comité Científico de la Fundación Centro de Estudios Históricos e Investigaciones locales de la región de Murcia. Recuperado de: htt ps://www.youtube.com/user/centroestudioslocal/videos 
Martínez Shaw, C. (2018). “Sistema atlántico o primera mundialización? Una perspectiva marxista”. En Gómez Alén, J., (ed.), Historiografía, marxismo y compromiso politico en España. Del franquismo a la actualidad. Madrid: Siglo XXI de España

Palmer, R. (1954). “The World Revolution of the West: 1763-1801”, Political Science Quarterly, 69(1),1-14

Revel, J. (1996). "Microananlyse et construction sociale”, en Revel, J. (dir.) Jeux d'échelles. La microanalyse à $l$ 'experience, pp. 15-36. Paris: Gallimard-Seuil

Subrahmanyan, S. (2001). "Du Tage au Gange au XVIe siècle : une conjoncture millénariste à l'échelle eurasiatique", Annales H.S.S, 56(1), 51-84. Recuperado de: https://www.persee.fr/doc/ahess_0395-2649_2001_num_56_1 _279934

Subrahmanyan, S. (2012). Impérios em Concorrência. Histórias Conectadas nos Séculos XVI e XVII. Lisboa: Imprensa de Ciencias Sociais

Vidal, C. (2012). "Pour une histoire globale du monde atlantique ou des histories conectées dans et au-delà du monde atlántique?”, Annales H. S. S., avril-juin, 2, 391-413. Recuperado de: https://www.cairn.info/revue-annales-20 12-2-page-391.htm\#

Vilar, P. (1962). La Catalogne dans l'Espagne moderne [Cataluña en la España moderna]. París: SEVPEN

Wallerstein, I. (1974-1989). The Modern World-System, 3 vols. New York: New York Academic Press

Zemon Davis, N. (1983). Le retour de Martín Guerre [El regreso de Martín Guerre]. Cambridge: Harvard University Press

Zemon Davis, N. (2006). Trickster Travels: A Sixteenth Century Muslim between Worlds [León el Africano: un viajero entre dos mundos]. New York: Hill and Wang.

Zemon Davis, N. (2011). "Decentering history. Local stories and cultural crossing in a global world", History and Theory, 50(2), 188-202.

\section{Notas}

1 Vidal (2012) recuerda que, si bien el concepto de historia atlántica es relativamente reciente, no lo es la práctica. Para ello se remonta a la obra pionera de Chaunu (1955-1959) como la controversia desatada entre Jacques Godechot y Robert Palmer (Godechot J.y Palmer, R., 1955; Godechot, J., 1956),, con Robert Soboul a propósito del concepto de revolución atlántica, en la década de la organización de la OTAN. En 1954 R. Palmer (1954) publica, continuando la propuesta de su maestro L. Gottschalk acerca de una revolución mundial en la cual distinguía una fase americana, otra francesa y una tercera napoleónica, cuya fecha final estimaba en 1815. A su vez, Godechot (1969) se centra en ese período y trata a la Revolución Francesa como una más "de las "revoluciones en cadena" que agitaron casi únicamente a los países de Occidente, o más aún, a los países costeros del Atlántico entre 1770 y 1748 ” y que entendía "como manifestaciones de una sola y única revolución, la revolución "liberal" o "burguesa”, cuyas causas profundas y generales fueron las mismas en todos los países, y variaron solo en función de las condiciones particular en encontradas en uno u otro lugar” (p. VI), ya había expuesto su visión del fenómeno revolucionario en su obra de 1956. Ambos historiadores, el francés y el americano presentaron conjuntamente en 1955 un informe titulado "Le problème de l'Atlantique". En todos los casos sus trabajos se remitieron al ciclo revolucionario iniciado en las postrimerías del siglo XVIII. La perspectiva americana y la europea eran muy diferentes. A fines de los años 60, la universidad Johns Hopkins daba un lugar importante a los intercambios de Europa y el Nuevo Mundo, y además a las relaciones con África, a compás de las investigaciones sobre la trata atlántica y la circulación entre ambas riberas, que tenía en Europa importantes representantes como los ya nombrados historiadores franceses, a los belgas H. Pirenne y Verlinden, al portugués V. Magalhaes Godinho y al inglés H. Hale. Pero recién en los años 90, la idea de una historia atlántica fue difundida a través de un seminario de historia del mundo atlántico, desarrollado en la universidad de Harvard, pero ahora se preocupa por los fenómenos de globalización del período moderno de modo diferente al de Braudel (1979) o al de Wallerstein (1974-1989), sino como una nueva historia transnacional "qui expérimente de nouvelle séchellesd'analyseafin de ne plus faire de la nation le cadre historique de référence” (Vidal, 2012, p. 392). La nueva historia atlántica constituiría según Games (1999), una forma de world history, aplicada al mundo atlántico y formada por las conexiones y redes de intercambios entre Europa, África y las Américas, del siglo XV al XIX. La nueva unidad de análisis está centrada en un océano que engloba a las otras (reino, colonia, imperio, continente, etc.) y la historia atlántica así concebida, se aleja de la visión europea. Más allá de estas observaciones, Chartier (2001) con ambivalencia, advierte sobre aquello que le inquieta: "De grands exemples montrent 
que ce défi peut être relevé, mais le fait que les plaidoyers les plus fervents en faveur d'une histoire globale n'aient souvent mobilisé que des références à des ouvrages publiés en une seule langue — l'anglais — n'est pas sans inquiéter..." (p. 120)

2 Conrad (2017) trabajo de análisis notable, sostiene que en la actualidad se vive un auge de la historia mundial/ universal/global, que ha tenido un extraordinario crecimiento en Estados Unidos y en otras partes del mundo anglófono. Esta afirmación es compartida con distintas posiciones favorables o desfavorables por el universo de los historiadores. Responde también a que "En muchos lugares, y en especial en las sociedades que han recibido mucha inmigración, la historia global también da respuesta a desafíos sociales y la necesidad de desarrollar una perspectiva del pasado que sea más inclusiva, menos estrictamente nacional" (pp. 7-8). Atribuye el que el interés se haya desplazado de la historia de la civilización occidental a la global a cambios en la composición social, cultural y étnica de la profesión, a la insuficiencia de los límites establecidos por las historias nacionales, a la revolución de las comunicaciones que se inició en los años 90 , a los medios informáticos que facilitan la realización de foros mundiales que facilitan la participación de multiplicidad de voces, nuevas perspectivas de estudio y a la lógica del trabajo en red.

3 La noción de "historia conectada" apareció por primera vez en el título de un dossier de la revista Annales. Histoire, sciencessociales (2001), “Temps croisées, mondes melées” que reunía contribuciones de contrapuestas de Subrahmanyan (2001) y de Gruzinsk (2001), comentadas por Chartier. Ya hemos hecho referencia a los espacios que universidades como las de Harvard y Johns Hopkins han dedicado estos estudios. En Francia existe una tradición de estudios africanos. La revista Annales ha destinado varios dossier y artículos a las "Cultures de l'ecrit en Afrique", en 2009, 64 (4), a "Les statuts sociaux au Japon” 2011 (4), a "Antilles et Europe (XVIII-XIX siècle)” y a "Memoires colonices”, en 2013 (1), a "Économie de l'Afrique contemporaine" a "Histoire du Maroc" en 2016 (4), a "Empires, colonies, conexions" en 2018 (1), a "Ecrirel'histoire de l'Islam moderne et contemporain” 2018 (2), pero no es un caso excepcional: la Rivista internazionale di storia della storiografia, 1999, Núm. 35, publicó un dossier dedicado a "World History Today: Chimera or Necessity?”, que comprendía artículos acerca de la historiografía africana, china y japonés, el último de los cuales producido por Conrad, en 2005, los núm. 47 y 48 contenía varios artículos sobre la historiografía china y su relación con la occidental, en el 2009, núm. 55, dedica espacio a la historia india, en el 2012, núm 62 vuelve a poner la atención en la reescritura de la historia china y su historiografía. La lista de revistas que merecen citarse es demasiado copiosa para este espacio, pero merece destacarse La publicación electrónica Nuevo mundo. Mundos Nuevos (CNRS/EHESS), en tres idiomas, la revista Historia Mexicana (El Colegio de México), https://historiamexicana.colmex.mx/index.php/RHM y para el mundo anglófono la Oxford Bibliography on Atlantic History (http://www.oxfordbibliographies.com/browse ?module_0=obo-9780199730414). De las estadounidenses puede citarse Hispanic American Historical Review, U. de Duke.La tendencia apuntada por este historiador francés en el 2015 tiende a afirmarse y no solo en Francia, donde la polémica acerca de la posición de la presencia de estudios sobre África, Asia, Oceanía y América latina en la grilla de los programas de la enseñanza media llegó a los periódicos (Bertrand, ob. cit., ob. cit., p. 4, nota 1), y donde hace años diversas universidades destinan seminarios de investigación a la historia de los países asiáticos, a la historia africana y a la de Oceanía, sino en otros países como Inglaterra -donde el propio Bertrand revistó como investigador invitado en Oxford, donde imparte su cátedra S. Subrahmanyan- y en los Estados Unidos, en la New School for Social Science Research. Aun en España, donde ese movimiento se vincula al de la historia atlántica y la historia global, no solo revistas tradicionales dedican monográficos a tal problemática, sino algunas relativamente recientes como Culture and History (CSIC), cuyos vol. 3, No 1 (2014) y 5, No 2 (2016) contienen respectivamente los dossier titulados "Written Empires: Franciscans, texts and the making of early modern Iberian Empires" y "Empires: Concepts and New Research on the Hispanic world, 16th - 18th centuries". Estos estudios, cobran cada vez más visibilidad en las grillas de los programas universitarios, en las revistas académicas, como apunta Bertrand. Esto no significa que cultiven corrientes historiográficas homogéneas.

4 Chartier (2001), acerca de las exposiciones orales de Gruzinski y Subrahmanyan (2000), cuyas posiciones consideraba motivadas por “"le refus du cadre de l'État-nation comme si celui-ci pouvait délimiter, rétrospectivement, une entité sociale et culturelle déjà présente avant même son avènement politique ; refus des découpages traditionnels de la monographie historique explorant les spécificités d'une province, d'un « pays », d'une ville; refus, enfin, de l'approche micro-historique qui, selon S. Gruzinski, a fait « négliger le lointain” (p. 119). Zemon-Davies (2011).

5 Subrahmanyan (2012), en su capítulo dos, citando a Faroqui (1999). En ese capítulo y en el 3, realiza interesantísimas observaciones acerca del análisis y empleo de las fuentes locales, pero también de las crónicas portuguesas coetáneas (Bertrand, 2007).

6 Conrad (2017), enumera tres modos de hacer historia europeocéntrica que han interpretado hasta ahora las transformaciones a escala planetaria: a) el proceso general de modernización se originó en Europa y desde allí se fue diseminando en el planeta, con el avance de la razón universal, b) la modernidad es europea y aunque se la equipara con el avance de la razón universal, su difusión ya no se ve como un proceso de emancipación sino de privación y c) las transformaciones no derivan del contacto con Occidente sino a partir de los propios recursos culturales indígenas (teleología del desencantamiento universal, que se realiza en forma interna en cada sociedad).

7 Es el momento de las tesis regionales como las de Goubert (1960), de Vilar (1962; existe versión en castellano, 1978); de Le Roy Ladurie, quien se ocupó de una región en el marco de la historia agraria en Les Paysans de Languedoc(1966) y 
de Montaillou, villageoccitan, de 1294 a 1324 (1975; existe versión en castellano, 1988); o de Chacón (1979), ejemplos de una serie muy extensa.

8 En tanto la historia regional y la historia agraria querían excluir el dato inusual, desde la historia de las mentalidades rescataron su carácter significativo y hasta paradigmático: Ginzburg (1976; existe versión en castellano 2009); Zemon Davis (1983; existe versión en castellano, 1983); Levi (1985; existe versión en castellano, 1990). Levi (2018) ha producido un interesante artículo acerca de esta relación que ha permitido la exploración de experiencias, trayectorias y redes de una manera inédita. También exploraron otros hechos aislados en el campo de la historia social como la peste, Cipolla (1980) o las redes de poder en un concejo castellano, Contreras (1992).

9 Martínez Shaw (2015b), "De la historia local a la historia global”. Discurso de Ingreso. Comité Científico de la Fundación Centro de Estudios Históricos e Investigaciones locales de la región de Murcia (copia cortesía del autor). La cronología que propone para la globalización comienza casi un siglo antes que la propuesta por Gruzinski.

10 Para este autor, el proyecto político de los Austrias españoles habría adquirido forma a partir de la unión de las coronas entre 1580 y 1640 merced al aporte luso, cuyas redes planetarias en correspondencia con una forma de vida imperial y marítima impulsaron la creación de una primera construcción política de carácter verdaderamente global.

11 Para este historiador, el atlantismo que vincularía indisolublemente a las comunidades de uno y otro lado del Atlántico, responde a la proyección hacia del pasado de fenómenos del presente. Habría tenido su primera manifestación en la creación de la OTAN y se habría revestido con un ropaje nuevo para reforzar material e ideológicamente la hegemonía de EE.UU. Hausberger (2018) critica fundamentadamente la cronología de Bayly. Se refieren brevemente a la hegemonía estadounidense en cierta historia global, Hausberger y Pani (2018).

12 Señala como uno de los principales desencadenantes de las exploraciones de los siglos XV y XVI, el encarecimiento de los metales preciosos por agotamiento de las minas de plata en Europa, que hallaron en las americanas una riqueza hasta entonces desconocida. A partir de ese momento, los caminos de la plata formaron una red que abarcó Europa, Asia, África y América e involucró a españoles y portugueses. El papel jugado por la plata en la temprana globalización que Hausberger data entre los siglos XVI y XIX, ha generado trabajos conjuntos de dicho autor y Bonalian (2018) con algunos debates (Hausberger, 2019).

13 Conrad (2017) Recuerda con toda razón “que ningún historiador puede proceder sin comparaciones” (p. 40). Poseen un gran valor heurístico, pero también limitaciones, pues tiende a crear y reproducir historias sobre lo particular de las diversas naciones y civilizaciones y las interpretaciones excepcionalistas, aunque en la actualidad tienden a tomar en consideración el mundo más amplio que engloba su objeto de estudio.

14 Conrad, (2017); Adelman, (2017 en Etchechuri Barrera y Rodríguez Aycaguer, 2018).

15 Fernández-Armesto y Sacks (2012); Fernández-Armesto (2005); en el caso de Guidi y Armitage (2014), se retorna a la larga duración remontándose a los orígenes mismos del universo, "Historia Profunda" - unos 40.000 años de vida humana, desde los comienzos de la prehistoria - y finalmente la "historia del Antropoceno", que tendría su iniciación cuando el hombre adquiere los instrumentos materiales y mentales como para "afectar el medio ambiente a escala planetaria”.

16 Solo a modo de ejemplo: Darwin (2007; existe versión en castellano, 2012); Burbank y Cooper (2010; existe versión en castellano 2011); Hyden-Hanscho, Pieper y Stangl (2013); Macfarlane y Martin (2002; existe versión en castellano, 2006).

17 Por ejemplo, Zemon Davis (2006). 